Andrés Biehl y Patricio Velasco (editores), Pedro Morandé. Textos sociológicos escogidos (Santiago: Ediciones UC, 2017).

RESEÑA

\title{
LA CULTURA COMO EL PUNTO CIEGO DEL ORDEN SOCIAL
}

\author{
Josefina Araos Bralic \\ Instituto de Estudios de la Sociedad
}

\begin{abstract}
E 1 año 2011, Pedro Morandé inauguró la cátedra "Sociología del mundo de la vida", en la Universidad Católica, con la siguiente afirmación: "La sociedad no es otra cosa que una conversación". ${ }^{1}$ Aludiendo a la fenomenología de Gadamer, el sociólogo introducía un curso cuya premisa central era que la conciencia aparece, antes que nada, frente a un mundo y un lenguaje común. Así, Morandé intentaba explicar la vida social como un diálogo constante entre cada nuevo intérprete y la tradición de la cual es heredero; una tradición que lo antecede y condiciona, pero que también posibilita toda reflexión sobre la realidad.
\end{abstract}

Josefina Araos Bralic. Licenciada y magíster en historia por la Pontificia Universidad Católica. Investigadora en el Instituto de Estudios de la Sociedad (IES). Email: jaraos@ieschile.cl.

La autora agradece "la lectura y valiosas sugerencias de las distintas versiones de este documento a María Josefina Poblete, Joaquín Castillo, Daniel Mansuy, Claudio Alvarado, Santiago Ortúzar, Sebastián Adasme, Fernando Contreras, Manfred Svensson, Catalina Siles y Felipe Sánchez".

${ }^{1}$ La cita es tomada de la primera clase de Pedro Morandé en el curso "Sociología del mundo de la vida", dictado el segundo semestre del año 2011, y al que la autora de esta reseña asistió como oyente. Morandé está siguiendo a Hans Georg Gadamer en la reflexión que desarrolla en Mito y razón (Barcelona: Paidós, 1997). Esto aparece específicamente en el capítulo "Acerca de la fenomenología del ritual y el lenguaje". Al parecer, la imagen de Gadamer es inicialmente tomada de una referencia de Heidegger a Hölderlin, cuando afirma: "el arte expresa siempre de modo inmediato, brutal, sumido en la materia caliente de la tierra, lo que el habla hila a través de "ese diálogo que los hombres somos"”. 
No resulta extraño, entonces, que el origen del libro que acá reseñamos -Pedro Morandé. Textos sociológicos escogidos — ${ }^{2}$ haya sido precisamente una conversación. Así lo explicitan sus editores, Andrés Biehl y Patricio Velasco, al presentar esta importante compilación de ensayos destinada, en sus palabras, a "introducir el pensamiento" del sociólogo a las nuevas generaciones. Su objetivo principal es evidenciar la actualidad de las preguntas formuladas por Pedro Morandé, asegurando así que la conversación establecida con él siga, tal como aconseja la tradición hermenéutica, reproduciéndose (11).

La selección de Biehl y Velasco se estructura a partir de dos criterios. El primero es temático y articula las cinco grandes partes en las que se divide la compilación. Aunque se trata de un desafío difícil por la cantidad de tópicos abordados por Morandé, los editores se arriesgan al agruparlos en cinco ejes claves de su reflexión: la crítica a las "teorías de la modernización" asumidas por el desarrollismo latinoamericano y el llamado a problematizarlas por medio del estudio sistemático de nuestra cultura; la misión de la educación en el marco de sociedades globalizadas y el rol de la universidad en el cuidado de la "tradición sapiencial"; la afirmación de una "ecología humana" - concepto que recoge de Juan Pablo II- que haga posible habitar un mundo común, pero amenazado; el papel insustituible de la familia en la formación - la "ontogénesis" - de la persona, y, finalmente, su interés en la religión, que va desde la relación entre razón y fe hasta la permanencia del sacrificio en el mundo moderno. ${ }^{3}$ El interior de cada una de las secciones se organiza, a su vez, con un criterio temporal que distribuye cronológicamente los 19 ensayos reunidos en el libro. Esto se hace para dar cuenta de la "evolución del pensamiento" de Morandé, no tanto en términos de sus intereses, como de las influencias teóricas, remisiones y

${ }^{2}$ Andrés Biehl y Patricio Velasco, eds., Pedro Morandé. Textos sociológicos escogidos (Santiago: Ediciones UC, 2017). En adelante, este libro se citará tan sólo con su número de página en paréntesis. A esta publicación la siguieron el mismo año dos proyectos editoriales en torno a la obra de Morandé, permitiendo una suerte de encuentro en la recuperación de su pensamiento. Esta reseña no es otra cosa que un intento por responder a la interpelación ofrecida por tales iniciativas. Ver también Pedro Morandé, Cultura y modernización en América Latina (Santiago: IES, 2017); Sofía Brahm, ed., Pedro Morandé. Textos escogidos de antropología cristiana (Santiago: Ediciones UC, 2017).

${ }^{3}$ El resumen es apresurado, pero intenta cubrir las cinco secciones que los mismos editores describen en la presentación del libro. 
diálogos que fue estableciendo con el paso de los años (12). Por medio de esta estructura, Biehl y Velasco reúnen los diversos textos de un autor que, como señala Eduardo Valenzuela en el prólogo, "nunca publicó una obra sistemática" (19). Encontramos así ensayos publicados originalmente en revistas de centros de estudio de gran influencia a nivel local durante los años ochenta y noventa; conferencias dictadas en seminarios católicos y universitarios en Chile, América Latina y Europa; artículos para publicaciones científicas; capítulos para libros colectivos y síntesis de sus cátedras. ${ }^{4}$ De esta manera, los editores nos entregan un libro que permite identificar las permanentes y profundas inquietudes de Pedro Morandé, otorgándole al fin el espacio y reconocimiento que reclamaba su obra.

Uno de los principales méritos de los editores consiste en haber logrado dar unidad narrativa y conceptual a una obra que, hasta hoy, se encontraba dispersa. Ellos mismos sugieren esa unidad al sintetizar en una sola y fundamental pregunta todo el pensamiento de Morandé: la preocupación por el destino de las personas y los pueblos en el marco de sociedades altamente complejas y funcionalmente diferenciadas. "Pedro estuvo siempre alarmado por la reducción de la persona a un rol social y a una apertura puramente técnica al mundo que la rodea", afirman Biehl y Velasco (12). Esa misma alarma es la que explica otro interés permanente del sociólogo manifestado en estos ensayos: el problema de la constitución del valor que, siendo parte esencial de todo orden social, las sociedades modernas parecen abandonar; una renuncia que ocurre tanto en el plano de las instituciones — que se sostienen en el principio abstracto de la igualdad formal - como en la reflexión de las ciencias sociales, que surgen para explicar esa misma modernidad y que se someten voluntariamente a la aspiración de una neutralidad inalcanzable. ${ }^{5}$

${ }^{4}$ Esta valiosa información puede obtenerse en un anexo al final del libro que indica el origen de cada publicación. Permanece como un desafío para quienes están recuperando su obra acceder a fuentes que permitan reconstruir las instancias orales en las que muchos de esos textos aparecieron por primera vez.

5 Esto lo desarrolla Morandé en el primer capítulo de la compilación que reseñamos, pero lo profundiza en su libro fundamental de 1984 Cultura y modernización en América Latina. El autor formula esta suerte de renuncia de distintas maneras, todas presentes en la compilación: las crisis de sentido frente a la falta de respuesta a la pregunta por la finalidad (o bien, el nihilismo); la neutralidad valorativa en las ciencias; la introyección y privatización del sacrificio, entre otras. 
Estas discusiones, aunque fundamentales, no ocupan un lugar significativo en los debates académicos contemporáneos, por lo que esta compilación constituye un valioso impulso para recuperarlas, sobre todo en tiempos cuando la reflexión sobre las "grandes preguntas" — en términos del mismo Morandé- ha sido relegada a espacios cada vez más pequeños, hasta quedar casi en los márgenes de la academia. Ahora bien, coincidiendo con los editores de este libro en reconocer la vigencia y relevancia de las preguntas que atravesaron la producción intelectual de Morandé, quisiéramos en esta reseña añadir otro objetivo. ¿Es posible considerar vigentes también algunas de las respuestas que el sociólogo ofreció en sus ensayos?

Aunque no es posible hacer un análisis exhaustivo de cada una de ellas, quisiéramos detenernos en un planteamiento específico de Morandé que, a nuestro juicio, no ha perdido su actualidad. Dicho planteamiento guarda relación con su dura crítica a los paradigmas de modernización aplicados en América Latina, reflexión que constituye un elemento central de todo su pensamiento. Nuestro interés es el siguiente: de qué modo, a partir de esa crítica, Morandé desarrolla un concepto de cultura que se articula como el punto ciego que esos proyectos desconocen. Aunque esto es más explícito en la primera parte del libro, la categoría de cultura atraviesa todo el texto como un criterio desde el cual el autor busca mostrar la incapacidad del orden social moderno, a pesar de sus pretensiones, de dar cuenta integralmente de la realidad. ${ }^{6}$ En lo que sigue, nos detendremos en esa conceptualización, intentando subrayar el aporte de esa tesis a nuestra comprensión de la compleja relación entre el orden social — del tipo que sea- y los sujetos históricos que lo constituyen. Esperamos que este ejercicio ayude a continuar el valioso trabajo iniciado por Biehl y Velasco: la recuperación del pensamiento de un autor no sólo para darle el reconocimiento que merece, sino, sobre todo, para recordar que el conocimiento también se hace nuevo cuando dialoga con aquello que lo antecedió.

${ }^{6}$ El concepto clave en los textos más tempranos es explícitamente el de cultura; en los años noventa tiende a esconderse un poco, porque Morandé lo reformula desde la categoría de persona (y el énfasis en la familia). Así lo precisa el mismo Valenzuela en el prólogo del libro (25). 


\section{MODERNIDAD Y SOCIEDAD FUNCIONAL}

Como buen sociólogo, la modernidad ocupa un lugar central en la reflexión de Morandé. ${ }^{7}$ La entiende, entre otras cosas, como el proceso en el cual se articula una "organización funcional de la sociedad" (172), y describe con especial detalle las "transformaciones sociales revolucionarias" que se derivan de ella (170). Una de esas transformaciones guarda relación con lo que sería una experiencia específicamente moderna, y cuya importancia es difícil sobrestimar: ya no es posible, afirma Morandé, "observar el todo" (172). ${ }^{8}$ En el contexto de una sociedad crecientemente compleja y subdividida en múltiples sistemas, ninguna instancia —y menos aún una conciencia— puede reclamar "la representación de la unidad de lo real". Aunque esto siga siendo un problema esencial para las personas, el desafío se convierte en el mundo moderno en la "irrepresentabilidad por antonomasia" (140). Y, por lo mismo, la pregunta se va excluyendo o evadiendo de manera progresiva. En el ámbito específico del saber, Morandé describe este fenómeno como la toma de conciencia del observador de la relatividad y contingencia de su propio punto de vista. No es raro entonces que el conocimiento adquiera un estatuto "provisional" que lo vuelve objeto de comprobación empírica y eventual superación (169). Morandé conceptualiza esta relatividad del conocimiento con la idea del "punto ciego", categoría desde la cual establecerá un diálogo directo con la teoría de sistemas de Niklas Luhmann. En este sentido, señala el autor, "desde la organización funcional de la sociedad (...) no es posible encontrar un punto de observación que considere la totalidad de los factores, puesto que toda observación tiene un punto ciego. Observar es diferenciar y nadie se puede situar simultáneamente en los dos lados de lo diferenciado" (172). ${ }^{9}$

${ }^{7}$ En términos de su emergencia histórica, Morandé discute la identificación de la modernidad con la Ilustración. Según el autor, se ha ocultado el papel del "barroco" en ese proceso, que fue a su juicio la "primera expresión cultural 'ecuménica' y moderna" (111). En el texto que reseñamos, Morandé aborda en varias ocasiones el proceso de emergencia de la modernidad, ya sea describiendo la "modernidad latinoamericana", analizando la sociedad funcional, definiendo globalización, etcétera.

${ }^{8}$ Seguimos específicamente el capítulo 2 de la segunda sección del libro, pero el problema de la representación de lo real se encuentra en varios momentos, como al final de la primera parte.

${ }^{9}$ La reflexión de Luhmann sobre el punto ciego de los sistemas sociales se deriva de la distinción del autor entre sistema y entorno. Ver, entre otros, Niklas Luhmann, La sociedad de la sociedad (México: Herder, 2006). 
Morandé incorporó a Luhmann en su reflexión sobre la modernidad no sólo para describir la emergencia de la sociedad funcional (tema central en los trabajos del sociólogo alemán), sino también para explicar el impacto que tiene ese nuevo escenario en la experiencia individual. Así, adopta de él la polémica tesis sobre el desplazamiento de las personas desde el centro al "entorno" de las sociedades modernas (172). ${ }^{10}$ Durante mucho tiempo, parte importante de las humanidades y las ciencias sociales se ha resistido a aceptar una hipótesis que, en última instancia, niega el protagonismo de la conciencia humana en la explicación del orden social. ${ }^{11}$ Morandé, en cambio, la recoge para dar cuenta, a partir de ella, de aquello que Nietzsche describió como nihilismo. Este fenómeno interesó profundamente al sociólogo, constituyendo a su juicio el "horizonte vivencial" más característico del mundo moderno. Y para definirlo ocupa las palabras del mismo Nietzsche: se trata de "aquella situación en que los valores han perdido su validez [y, por ello], falta la finalidad, la respuesta a la pregunta por el porqué" (135). ${ }^{12}$ Establece, de este modo, una relación muy original entre Luhmann y Nietzsche, entendiendo el nihilismo como la "consecuencia metafísica" del hecho de que el ser humano no esté más en el centro del funcionamiento de la sociedad. Esta última puede prescindir ahora de la comprensión y voluntad de las conciencias que, supuestamente, constituían su fundamento (172).

Ahora bien, lo que podríamos entender como una implicancia problemática derivada de la organización funcional de la sociedad - y que Morandé reconoce en esos términos al hablar de la "crisis de sentido" que aparece en las sociedades modernas (173) - abre, al mismo tiempo, una oportunidad. El "punto ciego", que en el plano de las personas implicó la experiencia radical de no ser más la "medida de todo", opera

${ }^{10}$ Luhmann desarrolla en más de un texto esta polémica tesis. Ver como referencia general Niklas Luhmann, Sistemas sociales. Lineamientos para una teoría general (México D.F.: Anthropos - Universidad Iberoamericana - CEJA, 1998).

${ }^{11}$ La recepción crítica de Luhmann más influyente y conocida es la de Jürgen Habermas, quien cuestionó justamente el desplazamiento del sujeto del centro de referencias del orden social. Para seguir esta discusión, ver El discurso filosófico de la modernidad (Madrid: Taurus, 1993) y La lógica de las ciencias sociales (Madrid: Tecnos, 2002).

12 La cita del alemán se encuentra en el $§ 2$ de La voluntad de poder (Madrid: Edaf, 2006). 
también en los sistemas sociales sobre los cuales se configura el orden funcional. Y ese dato permite entonces situar sus límites, justo en el momento cuando parecieran desdibujarse o totalizarse. Aunque la autorreferencia de tales sistemas les permita actuar prescindiendo de su "entorno", sin este último — sin su heterorreferencia - no pueden siquiera constituirse. Las personas - y la cultura - no son entonces otra cosa que el punto ciego de sistemas que, aunque las desconozcan, las suponen. ${ }^{13}$

\section{CULTURA Y MODERNIZACIÓN}

Interesa la descripción de la sociedad funcional que ofrece Morandé, pues se vincula con una de sus reflexiones más tempranas y duraderas: la preocupación por la cultura. ${ }^{14}$ Esta relación no es necesariamente evidente, pues los espacios en que formuló cada idea no coincidieron temporalmente, y él tampoco parece haberlo explicitado en los términos que ensayaremos acá. Sin embargo, la compilación que reseñamos nos permite revisar de manera conjunta estos planteamientos, estableciendo así una relación valiosa para subrayar la vigencia de una hipótesis fundamental en la obra de Morandé. ${ }^{15}$ El autor llega a la cultura a partir de la crítica a los paradigmas de modernización que inspiraron a las ciencias sociales latinoamericanas, así como a los gobiernos que, apoyados

${ }^{13}$ Seguimos acá la interpretación que realiza Cecilia Bralic desde el arte en "La relación entre arte y cultura: acontecimiento y comunicación", Cátedra de Artes 1 (2005): 99-107.

${ }^{14}$ Reflexión que Morandé sistematiza en sus dos primeros libros: Ritual y palabra. Aproximación a la religiosidad popular latinoamericana (Santiago: IES, 2010) y el citado Cultura y modernización en América Latina. Y que aparece con claridad en la primera parte de la compilación ahora reseñada.

15 Es muy importante señalar que, aunque la relación que establecemos no apareció explícitamente en estos términos, Morandé sí desarrolla en más de una ocasión el vínculo entre Luhmann (que es desde donde describe la sociedad funcional y el problema del punto ciego) y la fenomenología (tradición en la que Morandé sitúa su comprensión de la cultura). Dos artículos poco difundidos del sociólogo son una excelente muestra de esta inquietud filosófica: "Técnica, sociedad funcional y reflexión metafísica. Heidegger y Luhmann", en Jaime Araos (ed.), Amor a la sabiduría. Estudios de metafísica y ética en homenaje al profesor Juan de Dios Vial Larrain (Santiago: Ediciones UC, 2004), y "Hermenéutica y auto-descripción en la teoría de Niklas Luhmann", Contenido. Arte, Cultura y Ciencias Sociales 4 (junio de 2014): 71-78. 
en ellas, implementaron programas de planificación y transformación durante la segunda mitad del siglo XX. ${ }^{16}$ El problema, en palabras sencillas, era el siguiente: aquello que en Europa había sido un proceso constatado y estudiado desde las ciencias sociales — esto es, la modernización-, en América Latina se asumió, sin cuestionamientos, como el destino al cual, por "deseable o inevitable", había que avanzar (37).

La recepción acrítica de lo que Morandé también llama "racionaliluminismo" elevó la modernización al estatus de categoría central en el análisis sociológico. Y, al asignarle este "carácter paradigmático", se renunció también a la pregunta por su propia "historicidad" (43). Como resultado, la sociología latinoamericana se convirtió en una "tecnología del cambio social programado", orientada a determinar las estrategias más eficientes — también las más justas - para alcanzar el desarrollo, sin nunca reflexionar sobre él como tal (44-45). ${ }^{17}$ Así, los diversos programas de modernización que desde los años cuarenta se enfrentaron de manera violenta y antagónica en la arena política para liderar la transformación social prometida compartían un mismo paradigma. Podían diferenciarse por el modelo escogido o por las causas identificadas como obstáculos para alcanzar dicha transformación, pero todos adolecían del mismo punto ciego: el olvido de la cultura (37). ${ }^{18}$

Este olvido no fue azaroso. En la "taxonomía" explicativa derivada del paradigma de modernización aceptado por las ciencias sociales de la región — que en el análisis de Morandé corresponde principalmente a la teoría de Talcott Parsons_- ${ }^{19}$, América Latina quedó en el estatus de

${ }^{16}$ Cómo el autor avanza desde la crítica al desarrollismo a la cultura se expresa con claridad en el capítulo 1 de la primera parte del libro que reseñamos (64).

${ }^{17}$ Esto aparece también explícitamente en Morandé, Cultura y modernización, 50.

${ }^{18}$ En la segunda parte de la compilación, cuando Morandé critica duramente lo que llama la "industrialización de las universidades", precisa que los sistemas funcionales de hecho "no necesitan de la cultura, ni la crean, ni la fomentan". Confirma así la idea de que la cultura es justamente aquello de lo que prescinden, y que por lo mismo no pueden ver (187). En la crítica al desarrollismo, es difícil no encontrar similitudes con la tesis de Mario Góngora, a quien Morandé por lo demás cita en más de una ocasión. Nos referimos específicamente al cuestionamiento de las "planificaciones globales", que el historiador plantea en Ensayo histórico sobre la noción de Estado en Chile en los siglos XIX y XX (Santiago: Editores La Ciudad, 1981).

${ }^{19}$ Morandé explica el impacto de la teoría de Parsons en América Latina gracias a la mediación de la influyente obra de Gino Germani (51). 
"sociedad tradicional", y sus componentes históricos y culturales fueron comprendidos sobre todo como "obstáculos" para el desarrollo. Lo que originalmente era una conceptualización sociológica para describir órdenes sociales diferentes, se volvió un binomio para jerarquizarlos. Lo problemático es que dejó de ser relevante "la observación atenta y rigurosa" de la realidad que cabía dentro de una "sociedad tradicional", transformándose esta última categoría en "la negación de todas y cada una de las características de la modernidad". En ese camino, América Latina quedó reducida a "un gran cajón de sastre donde puede caber lo que se quiera, puesto que no queda definido por lo que contiene, sino por lo que se sabe de antemano que le falta” (45). De aquí derivó el abandono del estudio de la particularidad cultural e histórica de la región, expresado en el alejamiento de la sociología de disciplinas como la antropología y la historia (43). ${ }^{20}$ La pregunta de la ciencia social ya no era aquella sobre la especificidad de América Latina para comprenderla y explicarla, sino una cuestión puramente técnica: qué pasos dar, y de qué manera, para convertirse — ¡al fin! — en una sociedad moderna.

Ya en 1982, en el artículo que inaugura esta compilación, Morandé acusa el "silencio" de la sociología latinoamericana (35), tesis que desarrollará luego con profundidad en Cultura y modernización en América Latina. El silencio no era otra cosa que el resultado de una parálisis intelectual producto del "agotamiento" de los "modelos sociológicos latinoamericanos" y de su "incapacidad para dar cuenta de la síntesis social y no de sus fragmentos" (36). Frente a esta parálisis, formula la siguiente pregunta: “¿Cómo podría la ciencia progresar en su conocimiento de la realidad social si su paradigma se transforma en mera afirmación de principios?" (38). A este silencio teórico se suma el hecho de que, hacia 1980, la aplicación de ese mismo paradigma había mostrado su fracaso en alcanzar — sin víctimas y con éxito- el ansiado desarrollo. La propuesta del sociólogo, como anticipamos, consiste en volver la mirada a la cultura, identificada como el gran ausente en el "marco categorial" de la reflexión sociológica latinoamericana (39). Las ciencias sociales debían abocarse en conjunto al "análisis del ethos latinoamericano", que en la perspectiva fenomenológica de Morandé se trata del estudio de las formas siempre particulares de habitar y valorar el mundo (64).

${ }^{20}$ La contracara de esta distancia es el acercamiento a la economía y la sicología. 
Para comprender este llamado debemos situarlo en la reflexión mayor de Morandé sobre la modernidad, esbozada al inicio de esta reseña. El "universalismo abstracto" que, según él, habría caracterizado a los proyectos modernizadores de América Latina se explica, al menos en parte, por la "totalización" de la lógica funcional con la cual operan los sistemas sociales en el mundo moderno (60). ${ }^{21}$ En sí misma, esa lógica no es necesariamente negativa. En cualquier caso, Morandé no emite un juicio valorativo sobre ella, pues le parece consustancial al desarrollo de sociedades altamente complejas. Así lo explicita a lo largo de sus textos escogidos, cada vez que intenta definir la "globalización", la "sociedad de la información" o el mundo moderno en general. ${ }^{22}$ Lo problemático aparece cuando esa forma de operar se extiende a otros ámbitos, como la economía, en la que Morandé se detiene. Ésta se delimita como sistema en la modernidad cuando establece el "principio de la eficiencia" como "criterio rector" de su acción, independizándose de otras instancias que no operan con el mismo "mecanismo organizacional" (243). Pero rápidamente —en la interpretación del sociólogo — tal mecanismo termina por incorporarse "a la vida social en su conjunto", impactando en última instancia la constitución misma de la "sociabilidad humana" (243). ${ }^{23}$

Como heredero de Heidegger, Morandé afirma que la "funcionalidad" propia de la era tecnológica es apenas una forma de aproximación al mundo — sólo un modo de "desocultar" o traer a la presencia- que, sin embargo, se generaliza. ${ }^{24}$ Se vuelve fundamental, entonces, para su argumentación, formular el problema del "punto ciego" de la manera más precisa posible, pues permite recordar que, a pesar de su "pretensión totalizante", la lógica funcional no alcanza a dar cuenta de todo lo que existe. Y es aquí donde entra la cultura, que vendría a ser el "punto ciego" a partir del cual los sistemas sociales reconocen sus propios límites. La cultura sería, en consecuencia, una suerte de recurso - de

${ }^{21}$ Morandé está hablando de una "pretensión totalizante" sobre todo por parte de la ciencia económica, pero cuya lógica termina expandiéndose a otros ámbitos.

22 En un momento el autor precisa: "No me parece que haya nada negativo en ello, excepto el hecho de que muchos se sienten arrastrados a buscar en este procedimiento lo que jamás podrán encontrar, como es la realización de la vocación humana" (176).

${ }^{23}$ Morandé desarrolla una crítica semejante cuando introduce la tesis de Polanyi en Morandé, Cultura y modernización, 72 y ss.

${ }^{24}$ Citando a Heidegger, precisa que en esa generalización se le oculta al hombre un "hacer salir lo oculto más originario", que le permitiría a su vez "experienciar la exhortación de una verdad más inicial" (136). 
recordatorio, tal vez - para contener esa tendencia casi insuperable de los sistemas sociales a excluir todo aquello que no se ajusta a sus clasificaciones. Cuando Morandé critica al "sociologismo latinoamericano", busca evitar, una vez más, la construcción de un paradigma abstracto y totalizante, un modelo ideal al que la realidad debe adecuarse. Eso sólo se resolvería desde el horizonte de la cultura: ese "otro lado" —el entorno- del sistema social. ${ }^{25}$ Este horizonte, en su autonomía, asegura la existencia de un espacio en el cual los sujetos históricos pueden entenderse y constituirse en su unicidad y especificidad. ${ }^{26}$

\section{EL PUNTO CIEGO DEL ORDEN SOCIAL}

Como señalamos al comienzo, la relación entre la reflexión sobre la cultura y el concepto del punto ciego de los sistemas sociales no fue explícita en la obra de Morandé. Esto podría explicar, quizás, que su propuesta no se haya introducido en algunas de las discusiones más intensas de su disciplina. Sin embargo, la compilación de Biehl y Velasco hace ahora posible tal ejercicio. Una de esas discusiones, y que ocupó un lugar importante en el panorama general de la teoría social desde los años setenta, fue aquella que buscó "traer de vuelta al Estado" al centro de los estudios sociales, luego de una larga hegemonía de los análisis estructurales y funcionalistas. ${ }^{27}$ Después de la profunda crisis

${ }^{25}$ La idea de "el otro lado" la tomamos directamente de la propuesta de Bralic antes citada: Bralic, "La relación entre arte y cultura".

${ }^{26}$ Es bastante explícito el esfuerzo de Morandé por evitar nuevas universalizaciones, como se ve en el cierre del capítulo 1 de la primera sección del libro que reseñamos: "El ciclo de la sociología latinoamericana de los últimos treinta años es, simultáneamente, un paréntesis, una laguna en la continuidad intelectual de la región. En tanto ella no sea superada se hace inmenso el riesgo de volver a constituir un paradigma de carácter universalista y abstracto que, por no encontrar nunca la realidad social, termine por inventarse una hipostasiando sus categorías" (64).

${ }^{27}$ La expresión la tomamos de la emblemática frase de Theda Skocpol, "Bringing the state back in", que dio título al artículo donde sistematizó diversos trabajos que estaban retomando el interés en el estudio del Estado desde los años setenta. Aunque ella pertenece a una línea de investigación más asociada al análisis empírico de la ciencia política, la premisa se extiende a otras escuelas y disciplinas que en los años siguientes recogieron también esta preocupación. Los estudios subalternos y poscoloniales, por ejemplo, de alguna manera se vinculan también a este reposicionamiento del protagonismo del Estado en la investigación social. Véase Theda Skocpol, "Bringing the State Back In: Strategies of Analysis in Current Research", en Bringing the State Back In (Cambridge: Cambridge University Press, 1985). 
experimentada por el enfoque positivista tradicional, que había privilegiado la dimensión lineal e institucional de las "historias nacionales", este reposicionamiento del Estado en la investigación social se realizó, eso sí, sobre la base de una mirada sumamente crítica sobre el mismo. Esto, considerando además la trayectoria histórica del siglo XX, que difícilmente permitía mantener una mirada demasiado optimista sobre su papel en las sociedades modernas.

Aunque son varios los autores que participaron en esta discusión, queremos detenernos en el influyente trabajo de James C. Scott, pues su tesis parece particularmente convergente con los planteamientos de Morandé que aquí hemos revisado. ${ }^{28}$ En su emblemático libro Seeing like a State, Scott describe los devastadores efectos de lo que denomina "ideología alto-modernista" (high-modernist ideology). Esta ideología habría inspirado los casos más paradigmáticos de autoritarismo estatal del siglo XX, que operaron sobre las comunidades locales con un espíritu irracionalmente optimista respecto de los beneficios de una realidad ordenada a partir del criterio exclusivo de la ciencia y la industria. ${ }^{29}$ Scott intenta explicar el fracaso de los grandes proyectos de planificación central por la exclusión - en el mejor de los casos, porque lo ignoran o desvaloran; en el peor, porque quieren eliminarlo - del "valioso conocimiento" arraigado en las prácticas de toda comunidad local. ${ }^{30}$ Esa exclusión se deriva justamente de una ideología que sólo considera

${ }^{28}$ Para mencionar algunos de los trabajos más emblemáticos, véase Charles Tilly, The Vendée: a sociological analysis of the counterrevolution of 1793 (Cambridge: Harvard University Press, 1964); Philip Corrigan y Derek Sayer, The Great Arch: English State Formation as Cultural Revolution (Oxford: Basil Blackwell, 1985).

29 James C. Scott, Seeing Like a State: How Certain Schemes to Improve the Human Condition Have Failed (Binghamton, N.Y.: Yale University Press, 1998), 4. Scott no forma parte directa de la escuela de Skocpol, pero sí de aquellos estudios que recuperan el protagonismo estatal en la explicación de los procesos históricos. Por otro lado, la influencia de Scott en las ciencias sociales es bastante transversal, pero probablemente la historia cultural del Estado en América Latina sea uno de los ejemplos más claros de su recepción. Ejemplo de esto es el trabajo de Gilbert M. Joseph y Daniel Nugent (eds.), Aspectos cotidianos de la formación del Estado. La revolución y la negociación del mando en el México moderno (México D.F.: Era, 2002). En una entrevista del año 2012, se explicita esta influencia transversal de Scott: http://historiaglobalonline.com/2012/12/05/james-c-scott-el-profesor-queaprende-de-los-campesinos/.

${ }^{30}$ Scott, Seeing Like a State, 6. Ese "valioso conocimiento" Scott lo conceptualiza recuperando de la tradición griega el término "metis". 
su propio saber como relevante y eficiente para intervenir sobre la vida social. Al igual que en la tesis de Morandé, para Scott la acción del Estado en sí misma tiende a desconocer o despreciar la sabiduría que impregna y al mismo tiempo se recrea en la experiencia cotidiana de las personas. ${ }^{31} \mathrm{Y}$ esa ignorancia se vuelve especialmente problemática por el hecho de que es ése el espacio concreto donde tienen lugar las políticas que ese Estado — sin considerarlo- despliega. ${ }^{32}$

Scott describe este desencuentro entre el Estado y la sociedad en la última parte de su libro, titulada "The missing link". ${ }^{33}$ La clave para entender el fracaso - y también la violencia- de las experiencias totalitarias del siglo pasado residiría en este eslabón perdido entre las personas y la acción estatal. Ahora bien, aunque se concentre en casos particulares y en especial en modelos autoritarios, la tesis de Scott es una crítica general al Estado moderno. Y es justamente eso lo que pone en evidencia el diálogo con la propuesta de Morandé aquí descrita. Más allá de la coincidencia en la formulación general que ambos autores hacen de la acción del Estado moderno, hay una especial vinculación a la hora de poner en valor el conocimiento local que tal Estado desprecia. La cultura en Morandé y la "metis" en Scott constituyen ese ámbito donde operan, paradójicamente, las mismas lógicas que lo ignoran. Es, por tanto, también el lugar donde se puede observar la siempre tensa relación entre el Estado y la sociedad.

Para mostrar de modo más concreto aquello en lo que consiste el "conocimiento práctico" en el cual se encuentran Scott y Morandé, nos detendremos un momento en el análisis que ambos realizan del "problema" de la informalidad, fenómeno tan extendido en las sociedades "periféricas" que, como la latinoamericana, estudian los dos autores. La informalidad ha sido objeto de una profunda reflexión en la fenomenología, que entiende la vida social como una compleja relación entre aquella realidad que se manifiesta y la que siempre (por su misma realidad lingüística) permanece latente. ${ }^{34}$ En este sentido, el enfoque

${ }^{31}$ Scott, Seeing Like a State, 313.

${ }^{32}$ Ibídem, 319.

${ }^{33}$ Ibídem, 307-57.

${ }^{34}$ Seguimos acá sobre todo la argumentación de Goffman acerca de la dinámica del mostrar-ocultar de la realidad, así como su reflexión sobre la estructura de la facticidad (análoga a la informalidad). Véase Erving Goffman, La presentación de la persona en la vida cotidiana (Buenos Aires: Amorrortu, 1971). 
fenomenológico se ha interesado por el mundo informal en la medida en que constituye el ámbito de la aplicación práctica y cotidiana de los principios abstractos y generales que estructuran todo orden social. ${ }^{35}$ De esta manera, ha intentado abandonar la comprensión de la informalidad como un mero problema o defecto del funcionamiento de la sociedad, para definirlo como aquel espacio sin el cual la formalidad no puede configurarse. Esto no es muy distinto de la formulación desarrollada por Scott en la obra que hemos citado. En su detallada descripción de lo que él denomina "metis" — también el "know-how", "sentido común" o simplemente "experiencia"-, Scott conceptualiza la informalidad como la realidad fáctica de la que depende, necesariamente, toda acción centralizada; en el fondo, toda "norma social". ${ }^{36} \mathrm{Y}$ señala respecto de la relación entre ambos lados: "El orden formal, para ser más explícito, es siempre y en un grado considerable parasitario de los procesos informales, que no son reconocidos por el esquema formal, sin los cuales éste no podría existir y los que por sí solo no puede crear o mantener" ${ }^{37}$ Como se ve, Scott no describe la relación entre la formalidad y la informalidad para que la primera tolere a la segunda. Lo que quiere es que esta última se reconozca como el lugar donde lo formal puede efectivamente aparecer; el plano donde las reglas explícitas pueden imprimirse y volverse eficaces.

Morandé realiza una reflexión semejante sobre esta relación, aunque la referencia explícita al fenómeno de la informalidad no está en los artículos del libro que reseñamos, sino en el registro de una de sus cátedras. En el mismo curso de "Sociología del mundo de la vida" al que hicimos referencia al inicio, y apoyándose en la fenomenología, Morandé afirmó que "no sólo tenemos que ver la estructura formal de la sociedad, sino también la informal que es la que se encarga de acomodar las disposiciones idealizadas a las situaciones concretas, y hacer una situación fácticamente realizable". ${ }^{38} \mathrm{Al}$ igual que en Scott,

${ }^{35}$ Respecto de la aplicación práctica de principios generales, se suman a Goffman los trabajos de Alfred Schutz y Harold Garfinkel. Ver Alfred Schutz y Thomas Luckmann, Las estructuras del mundo de la vida (Buenos Aires: Amorrortu, 1977); Harold Garfinkel, Estudios en etnometodología (Barcelona: Anthropos, 2006).

${ }^{36} \mathrm{Scott}$, Seeing Like a State, 311.

${ }^{37}$ Ibídem, 310 (traducción propia).

${ }^{38}$ La cita forma parte de los apuntes tomados por quien escribe, habiendo participado del curso "Sociología del mundo de la vida" dictado por el profesor Morandé en el ISUC durante el año 2011. 
Morandé quiere subrayar el valor sociológico de un espacio que, desde la lógica del sistema social —esto es, el Estado-, no logra reconocerse, y que sin embargo hace posible que la formalidad del orden social pueda constituirse. De este modo, ambos autores enfatizan la autonomía y anterioridad de la cultura, para usar los términos de Morandé, frente a los demás niveles de la vida social. Este reconocimiento no constituye una mera afirmación de principios o un ejercicio puramente reivindicativo, sino que ofrece un cambio de perspectiva que modifica nuestra comprensión sobre la tensa y cotidiana relación entre el Estado y las personas. La manera en que ambos autores entienden el caso específico de la informalidad permite reinterpretar esa relación, afirmando que ella no es apenas el lugar de la falla y del error de la acción estatal, sino el de su emergencia y verificación. La cultura es así, en última instancia, la condición de posibilidad de un ordenamiento con el que la conciencia moderna insiste en identificarse, olvidando que allí no podrá nunca reconocerse.

\section{PALABRAS FINALES}

Por la naturaleza del trabajo intelectual de Pedro Morandé, así como por la visibilización que su obra ha alcanzado el último año gracias a proyectos editoriales como éste, hemos optado por un tipo de reseña más ensayístico que descriptivo. El objetivo ha sido no sólo dar cuenta de las características del libro presentado, sino, sobre todo, problematizar algunas de las tesis desarrolladas por el autor. Intuimos que un ejercicio así puede servir para mostrar la vigencia de la propuesta de Pedro Morandé, que reclama, quizás más que antes, su posicionamiento en los grandes debates de su disciplina. Pero su trabajo también puede aplicarse en las discusiones más contingentes que copan hoy nuestro debate público y que, como bien muestran los textos escogidos por Biehl y Velasco, el sociólogo ha seguido con especial atención. El lenguaje de Morandé es, sin duda, complejo; pero no abstracto. Y aunque continúa pendiente la comprobación empírica de sus arriesgadas hipótesis, en la lectura de este libro uno puede confirmar la convicción de que, si el pensamiento no está al servicio de la realidad que observa, no sirve para nada. Esto no debe confundirse con el espíritu de una sociología comprometida que él tanto criticó en sus primeros trabajos. Puede que 
haya algo emancipatorio en la preocupación de Morandé por la cultura y la persona, pero su interés no reside en afirmar la supremacía de ambas para ponerlas al servicio de la transformación del orden social, alcanzando así una supuesta liberación definitiva. Lo que Morandé espera es reivindicar el espacio de la cultura como una instancia autónoma, donde el ser humano puede recordar que, con independencia de lo que ocurra en el orden social, no depende de éste para constituirse, y menos aún para realizar su vocación y ejercer su libertad. Al mismo tiempo, nos recuerda que ese mismo orden social puede perfeccionarse y superar sus puntos ciegos, sólo en la medida en que desarrolle mecanismos para incorporar esa experiencia que tan a menudo desconoce.

La preocupación transversal de Morandé por la cultura —que es también aquella por la persona- no puede entenderse si no la situamos en su profunda identidad cristiana. Hoy puede parecer poco estratégico reconocer este tipo de premisas, pues se asume que contamina la observación imparcial de los fenómenos sociales. Pero en este autor no es posible ocultarlo, pues en último término es desde el diálogo con el magisterio que Morandé intentó responder a la radical pregunta, tan bien identificada por los editores de sus ensayos, acerca del destino de las personas en la sociedad contemporánea. Su principal originalidad en este sentido reside en el hecho de haber mostrado la capacidad para leer reflexivamente esa doctrina. Morandé ha estado siempre consciente de que la fe no remite a una obediencia ciega, sino que requiere - urgentemente - de intérpretes capaces de responder a la "exhortación originaria" de la realidad, transformándola, antes que por la acción, por el testimonio único e irrepetible que se manifiesta en cada uno de nosotros. Ese lenguaje común del que venimos y al que siempre volvemos, y que en los ensayos compilados en este libro se aprecia con especial profundidad.

\section{BIBLIOGRAFÍA}

Biehl, Andrés \& Patricio Velasco, eds. Pedro Morandé. Textos sociológicos escogidos. Santiago: Ediciones UC, 2017.

Brahm, Sofía, ed. Pedro Morandé. Textos escogidos de antropología cristiana. Santiago: Ediciones UC, 2017.

Bralic, Cecilia. "La relación entre arte y cultura: acontecimiento y comunicación". Cátedra de Artes 1 (2005): 99-107. 
Corrigan, Philip \& Derek Sayer. The Great Arch: English State Formation as Cultural Revolution. Oxford: Basil Blackwell, 1985.

Gadamer, Hans Georg. Mito y razón. Barcelona: Paidós, 1997.

Garfinkel, Harold. Estudios en etnometodología. Barcelona: Anthropos, 2006.

Goffman, Erving. La presentación de la persona en la vida cotidiana. Buenos Aires: Amorrortu, 1971.

Góngora, Mario. Ensayo histórico sobre la noción de Estado en Chile en los siglos XIX y XX. Santiago: Editores La Ciudad, 1981.

Habermas, Jürgen. El discurso filosófico de la modernidad. Madrid: Taurus, 1993. - La lógica de las ciencias sociales. Madrid: Tecnos, 2002.

Joseph, Gilbert M. \& Daniel Nugent, eds. Aspectos cotidianos de la formación del Estado. La revolución y la negociación del mando en el México moderno. México D.F.: Era, 2002.

Luhmann, Niklas. Sistemas sociales. Lineamientos para una teoría general. México D.F.: Anthropos - Universidad Iberoamericana - CEJA, 1998.

—. La sociedad de la sociedad. México: Herder, 2006.

Morandé, Pedro. Cultura y modernización en América Latina. Santiago: IES, 2017. . "Hermenéutica y auto-descripción en la teoría de Niklas Luhmann". Contenido. Arte, Cultura y Ciencias Sociales 4 (junio de 2014): 71-78.

. Ritual y palabra. Aproximación a la religiosidad popular latinoamericana. Santiago: IES, 2010.

—. "Técnica, sociedad funcional y reflexión metafísica. Heidegger y Luhmann". En Amor a la sabiduría. Estudios de metafísica y ética en homenaje al profesor Juan de Dios Vial Larrain, editado por Jaime Araos. Santiago: Ediciones UC, 2004.

Nietzsche, Friedrich. La voluntad de poder. Madrid: Edaf, 2006.

Schutz, Alfred \& Thomas Luckmann. Las estructuras del mundo de la vida. Buenos Aires: Amorrortu, 1977.

Scott, James C. Seeing Like a State: How Certain Schemes to Improve the Human Condition Have Failed. Binghamton, N.Y.: Yale University Press, 1998.

Skocpol, Theda. "Bringing the State Back In: Strategies of Analysis in Current Research". En Bringing the State Back In. Cambridge: Cambridge University Press, 1985.

Tilly, Charles. The Vendée: a sociological analysis of the counterrevolution of 1793. Cambridge: Harvard University Press, 1964. EP 